\title{
Bilateral Upper Extremity Edema in the Psoriatic Arthritis Case
}

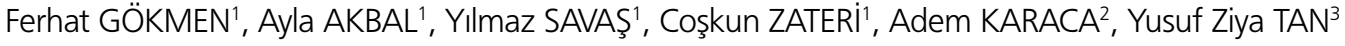 \\ ${ }^{1}$ Department of Physical Medicine and Rehabilitation, Onsekiz Mart University Faculty of Medicine, Çanakkale, Turkey \\ ${ }^{2}$ Clinic of Physical Medicine and Rehabilitation, Muş State Hospital, Muş, Turkey \\ ${ }^{3}$ Department of Nuclear Medicine, Onsekiz Mart University Faculty of Medicine, Çanakkale, Turkey
}

\begin{abstract}
Psoriatic arthritis (PsA) is a seronegative spondyloarthropathy characterized by peripheral arthritis, enthesis, spondylitis, and psoriasis. Lymphedema arises from the slowing of lymphatic flow because of inflammatory or noninflammatory diseases such as tumors, infections, bursitis, rheumatoid arthritis, and polymyalgia rheumatica. It is commonly encountered in one or more regions of distal extremities. Lymphedema is a rare complication of PsA, and it is commonly seen asymmetrically and in lower extremities. We aimed to report a case, who followed-up with diagnosis with PsA and with complaints of upper extremity swelling and bilateral upper extremity lymphedema diagnosed as a result of the review.

Keywords: Psoriatic arthritis, upper extremity, lymphoedema, anti-TNF alpha
\end{abstract}

\section{Introduction}

Psoriatic arthritis (PsA) is a chronic inflammatory rheumatic disease characterized by psoriasis and arthritis. Its clinical findings include tenderness in joints, pain, swelling, stiffness, dactylitis, and enthesis (1). Lymphedema is the formation of a swelling in a specific region of the body that is secondary to the accumulation of the lymph fluid under the skin due to pathological changes in the lymphatic flow. It commonly occurs in the lower extremities. Moreover, it can be observed on the face, neck, upper extremities, and genital region. The impairment in the lymphatic flow can be primary or secondary. Primary lymphedema is frequently observed in females and in during puberty. Secondary lymphedema occurs because of slowing in the lymph flow due to acquired conditions (2). Lymphedema is a rare extra-articular feature in PsA. In this study, a case followed up with PsA diagnosis and developing bilateral upper extremity lymphedema is discussed with current literature.

\section{Case Report}

A 39-year-old female patient who followed up because of PsA diagnosis visited our clinic with complaints of swelling in both hands and forearms and pain. Her medical history revealed that methotrexate therapy for PsA had been initiated 10 years ago (15 mg/week); however, she had discontinued the therapy because her complaints related to joints had decreased. Moreover, because of the occurrence of complaints of diffuse swelling in the left hand and forearm in addition to joint pain a few months after the discontinuation of the therapy, etanercept therapy had been initiated $(2 \times 25 \mathrm{mg} /$ week), resulting in a prominent improvement of the swellings of the leg and joint complaints. However, it was found that swellings in the right hand and left forearm had developed again in the patient, whose etanercept therapy had been discontinued because of pregnancy 3 years ago. The physical examination performed at admission to our clinic revealed psoriasis of the scalp, bouton- 


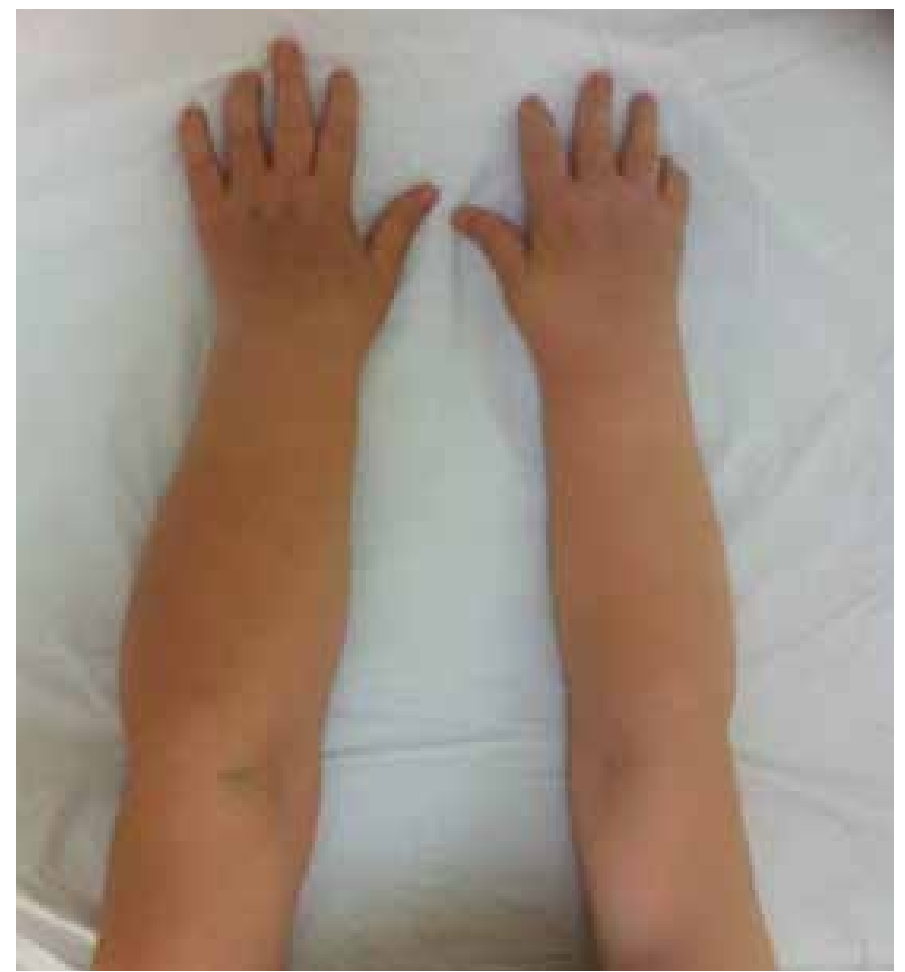

Figure 1. Diffuse swelling of both forearms associated with lymphedema

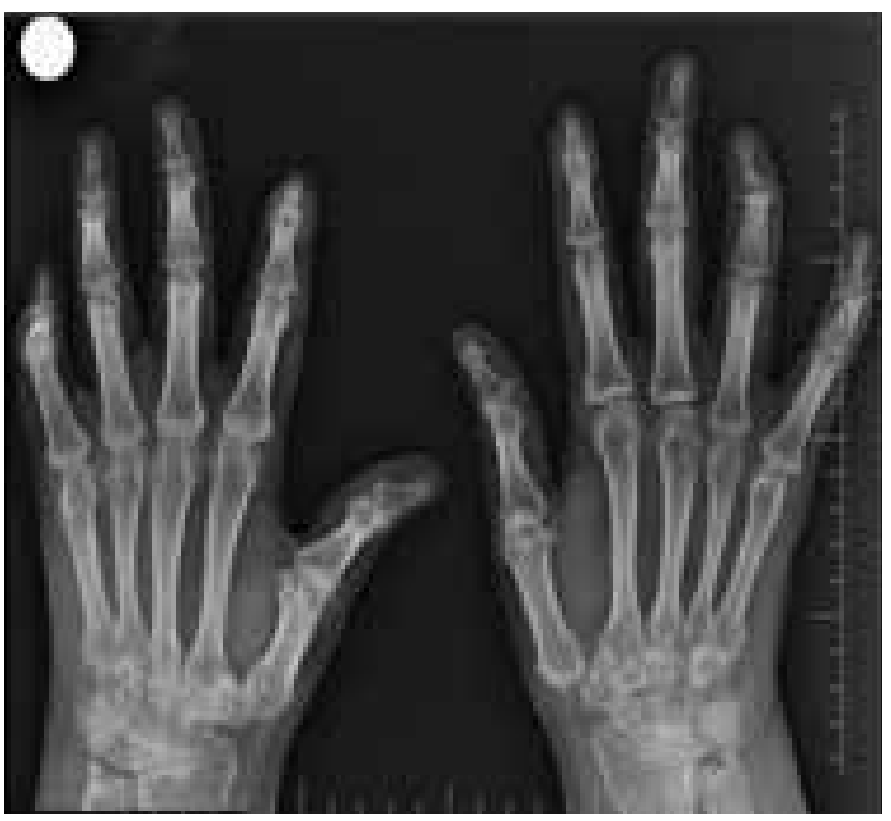

Figure 2. Wrist and finger deformities associated with psoriatic arthritis

niere deformity in the $5^{\text {th }}$ finger of the right hand, fusiform swelling in the $3^{\text {rd }}$ finger of the left hand, and diffuse swellings in the dorsum of the hand and from the wrist to the elbow (Figure 1). Other systemic findings of the patient were normal. In her laboratory tests, hemoglobin was $9.8 \mathrm{~g} / \mathrm{dL}$; erythrocyte sedimentation rate was $17 \mathrm{~mm} / \mathrm{h}$; C-reactive protein level was $1.02 \mathrm{mg} /$ $\mathrm{dL}$, rheumatoid factor was negative; anti-CCP was negative; and

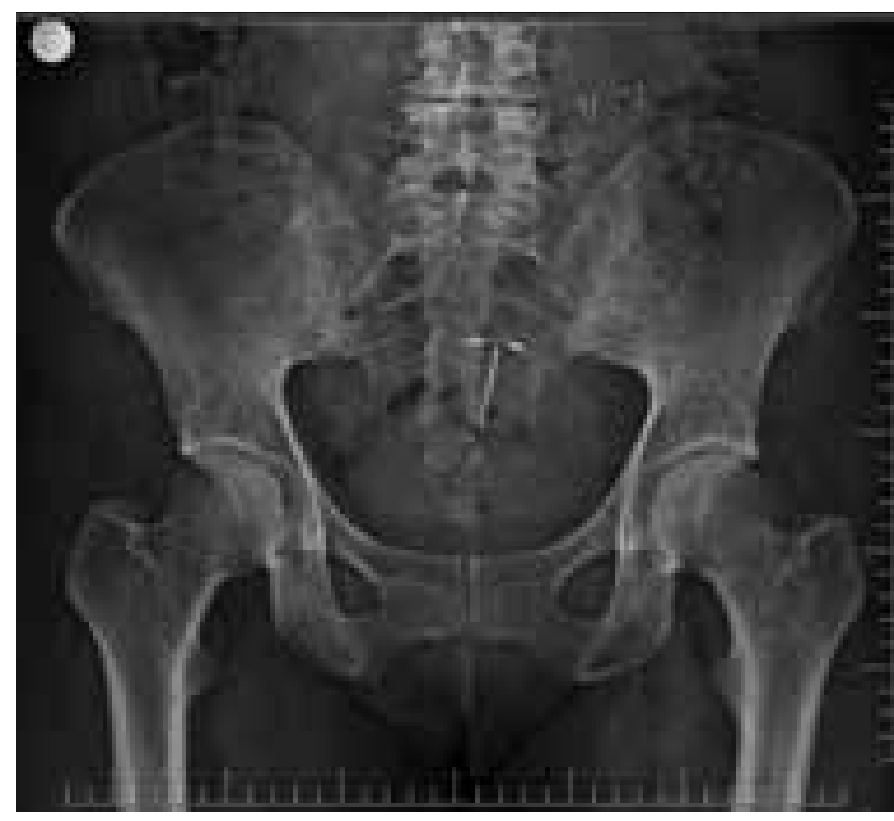

Figure 3. Bilateral sacroiliitis
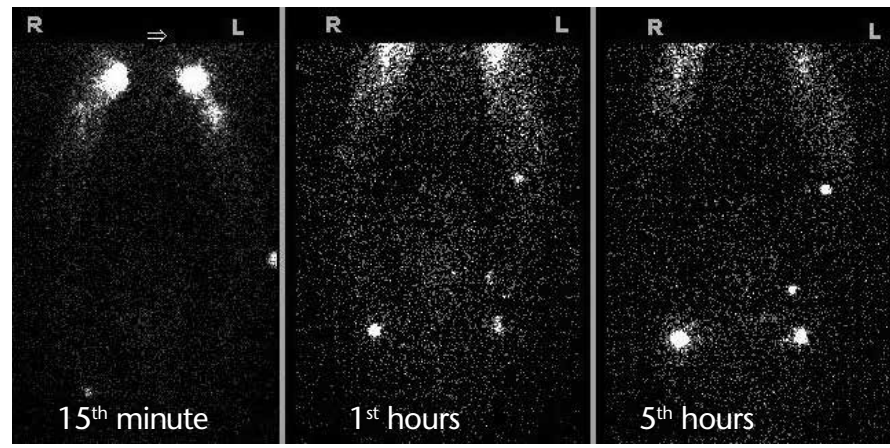

Figure 4 . In the images taken in the $15^{\text {th }}$ minute in anterior position in the lymphoscintigraphy of the upper extremity, the lymph nodes were slightly observed in the right axilla but not in the left axilla. In the late images taken in the $1^{\text {st }}$ and $5^{\text {th }}$ hours, lymph nodes were observed in both axillae but more prominent in the right axilla

serum liver and kidney function tests were within normal intervals. In direct radiographies, narrowing, erosion, and ankylosis in the carpal bones and in the spaces of the first finger metacarpophalangeal and interphalangeal joints (Figure 2) and bilateral sacroiliitis in the sacroiliac joint (Figure 3) were detected in both the hands. In the medical background of the patient, whose upper extremity arterial and venous Doppler ultrasonography (US) and mammography results were detected to be normal, no history of drug use, axillary surgery or radiotherapy, malignancy, thrombophlebitis, and allergic reaction that could cause edema in the upper extremities was found. Therefore, lymphedema was suspected. In the lymphoscintigraphy performed for the final diagnosis of lymphedema, activity involvement of the hands, forearms, and elbows was detected, which was consistent with lymphedema (Figure 4). The patient, who had been followed up with PsA diagnosis, was again initiated etanercept $(50 \mathrm{mg} /$ 
week) therapy. Her joint pain was observed to have regressed in the follow-ups, and partial improvement was observed in the swellings of both the forearms.

\section{Discussion}

PsA is a chronic inflammatory disease that affects the major joints, skin, and musculoskeletal system (1). During the course of PsA, many systems, including eyes, kidneys, heart, and lungs, can also be damaged. Lymphedema is an extra-articular involvement that is rarely observed in PsA cases. In the literature review, a few articles revealing the coexistence of PsA and lymphedema are found. Pathogenetic mechanism and the cause and effect relationship of lymphedema in patients with PsA cannot be exactly explained. Therefore, it is important to establish the differential diagnosis of other diseases leading to lymphedema at the beginning. For differential diagnosis, other diseases that can cause edema in the upper extremities, such as primary lymphedema, polymyalgia rheumatica, giant cell arteritis, remitting seronegative symmetrical synovitis with pitting edema syndrome, olecranon bursitis, tumor, and infections, must be considered (3-5).

After ruling out other factors, the cause of edema is mainly explained with two mechanisms in cases suspected of PsA-induced edema. The first mechanism is tenosynovial involvement, which has been reported only in a few cases. In the study of Quarta et al. (6), the cause of edema was reported to be tenosynovial involvement in a case with normal lymph flow. Similarly, Salvarani et al. (7) claimed that edema in their patient might have resulted from tenosynovial involvement. Therefore, the investigation of tenosynovial involvement through MRI or US is recommended for patients with upper extremity edema. The other mechanism is the assertion that lymphatic vessels' being affected because of inflammation, basal membrane thickening in the lymph capillary, and collagen storage cause fibrosis and accordingly, slowing in the lymphatic flow and obstruction (8). Case reports, which demonstrate that the lymphatic flow improves with decreased inflammation after the administration of etanercept, cyclosporine, and adalimumab therapies, support the relationship between inflammation and lymphedema (9-11). As in our case, although lymphedema had previously remarkably improved with etanercept therapy, no response was obtained then. This suggests that inflammation is not responsible for the etiopathogenesis of lymphedema by itself. Its pathogenesis is not exactly known because there are a few case reports, and there is no randomized study on it.

The diagnosis of lymphedema is mostly established on the basis of clinical criteria. Patients have complaints of swelling, somnolence, and pain. In physical examination, the clarity of bone protrusions and skin layers is found to be disappeared. Asymmetry and cavitation with compression are observed in the extremities (12-14). Lymphoscintigraphy and MRI can be performed in case of unknown etiology. However, they are generally not required, and their applications are limited to researches $(12,13)$. Besides PsA, other causes of chronic lymphedema, such as post-mastectomic edema and axillary lymphatic system surgery, must be investigated (15). Decreased phasic change, echogenic thrombin, vein wall stenosis, and appearance of collateral vessels can be observed in edema developing post-mastectomy. Moreover, in patients with post-mastectomy edema, arterial Doppler US of swollen extremity can reveal increased arterial flow (16). In our case, no surgical history was defined, and no hemodynamic abnormality was found in venous Doppler US.

In general, the treatment of lymphedema focuses on decreasing the swelling in the extremity, controlling symptoms, and reducing complications (17). Because lymphedema associated with PsA and rheumatoid arthritis can be related to the inflammation process, it is important to closely follow-up these patients and to take the disease under control in patients developing lymphedema (8). Disease-modifying drugs were used in the treatment of lymphedema associated with rheumatoid diseases; however, they were inadequate most of the time $(9,18)$. In some cases, intra-articular corticosteroid injections can result in the resolution of lymphedema in a short time $(19,20)$. Grillet et al. (21) found a prominent decrease in lymphedema with pulse methylprednisolone therapy in their case. With regard to anti-TNF therapy, in the study of Lekpa et al. (10), they followed up a patient with PsA receiving etanercept therapy, and they observed a significant resolution in lymphedema. Similarly, Tong et al. reported a notable improvement in lymphedema of a patient with PsA receiving adalimumab therapy (11). In our patient, although an improvement was observed in the clinical and laboratory parameters and complaints of the patient with the addition of etanercept therapy to leflunomide therapy, no apparent healing was observed in the swelling associated with lymphedema.

\section{Conclusion}

Lymphedema is a rarely observed complication in PsA. First of all, other factors that can cause the development of edema must be ruled out. Although there is not enough evidence regarding the treatment of lymphedema in patients with PsA, we believe that the suppression of inflammation can reduce lymphedema.

Informed Consent: Written informed consent was obtained patient who participated in this case.

Author contributions: Concept - F.G.; Design - F.G, AA.; Supervision - Y.S, C.Z.; Resource - F.G, A.K; Materials - F.G, Y.Z.T.; Data Collection and/ or Processing - F.G, A.A.; Analysis and/or Interpretation - F.G, A.A, Y.S, C.Z.; Literature Search - F.G, A.K.; Writing - F.G, A.A.; Critical Reviews - A.K, Y.Z.T.

Conflict of Interest: No conflict of interest was declared by the authors.

Financial Disclosure: The authors declared that this study has received no financial support.

\section{References}

1. CJ Michet. Psoriatic Arthritis. In: Kelley WN, Haris ED, Ruddy S and S. CB, editors. Textbook of Rheumatology. Philadelphia: WB Sounders Campany; 1993. 974-84.

2. Szuba A, Rockson SG. Lymphedema: classification, diagnosis and therapy. Vasc Med 1998;3:145-56. [CrossRef]

3. Mc Carty DJ, O'Duffy JD, Pearson L, Hunter JB. Remitting seronegative symmetrical synovitis with pitting edema. RS3PE syndrome. JAMA 1985;254:2763-7. [CrossRef] 
4. Salvarani C, Gabriel S, Hunder GG. Distal extremity swelling with pitting edema in polymyalgia rheumatica. Report on nineteen cases. Arthritis Rheum 1996;39:73-80. [CrossRef]

5. Macfarlane J D, van der Linden SJ. Leaking rheumatoid olecranon bursitis as a cause of forearm swelling. Ann Rheum Dis 1981;40:309. 11. [CrossRef]

6. Quarta L, Corrado A, d'Onofrio F, Maruotti N, Cantatore FP. Two cases of distal extremity swelling with pitting oedema in psoriatic arthritis: the different pathologicalmechanisms. Rheumatol Int 2010;30:1367-70. [CrossRef]

7. Salvarani C, Macchioni P L, Veneziani M, Rossi F, Lodi L, Baricchi R, et al. Upper limb lymphedema in psoriatic arthritis. J Rheumatol 1990;17:273-4

8. Yamamoto T, Nishioka K. Psoriasis arthropathy and lymphedema. J Dermatol 2002;29:812-4. [CrossRef]

9. Mulherin D M, FitzGerald O, Bresnihan B. Lymphedema of the upper limb in patients with psoriatic arthritis. Semin Arthritis Rheum 1993;22:350-6. [CrossRef]

10. Lekpa F K, Economu-Dubosc A, Fevre C, Claudepierre P, Chevalier $X$. Efficacy of etanercept in lymphedema associated with psoriatic arthritis. J Rheumatol 2009;36:207-8.

11. Tong D, Eather S, Manolios N. Psoriatic arthritis and chronic lymphoedema: treatment efficacy by adalimumab. Clin Rheumatol 2009;28:1349-50. [CrossRef]

12. Cheville AL. Current and future trends in lymphedema management: implications for women's health. Phys Med Rehabil Clin N Am 2007;18:539-53. [CrossRef]
13. Rockson SG, Miller LT, Senie R, Brennan MJ, Casley-Smith JR, Foldi $\mathrm{E}$, et al. American Cancer Society Lymphedema Workshop. Workgroup III: Diagnosis and management of lymphedema. Cancer 1998;83:2882-5. [CrossRef]

14. Gerber LH. A review of measures of lymphedema. Cancer 1998;83:2803-4. [CrossRef]

15. Stanton AW, Levick JR, Mortimer PS. Current puzzles presented by postmastectomy oedema (breast cancer related lymphoedema). Vasc Med 1996;1:213-25.

16. Svensson W E, Mortimer PS, Tohno E, Cosgrove DO. Colour Doppler demonstrates venous flow abnormalities in breast cancer patients with chronic arm swelling. Eur J Cancer 1994;30A:657-60. [CrossRef]

17. Szuba A, Achalu R, Rockson SG. Decongestive lymphatic therapy for patients with breast carcinoma associated lymphedema. Cancer 2002;95:2260-7. [CrossRef]

18. Dacre JE, Scott DL, Huskisson EC. Lymphoedema of the limbs as an extra-articular feature of rheumatoid arthritis. Ann Rheum Dis 1990;49:722-4. [CrossRef]

19. Bamji A. Limb lymphoedema in rheumatoid arthritis. Ann Rheum Dis 1991;50:407. [CrossRef]

20. de Silva RT, Grennan DM, Palmer DG. Lymphatic obstruction in rheumatoid arthritis: a cause for upper limb oedema. Ann Rheum Dis 1980;39:260-5. [CrossRef]

21. Grillet B, Dequeker J. Rheumatoid lymphedema. J Rheumatol 1987; 14:1095-7. 